\title{
Evaluation of Halopelvic Traction for Curve Correction in Spinal Deformities
}

\author{
${ }^{1}$ Dr. Raj Singh, ${ }^{2}$ Dr. Sukhbir S Sangwan, ${ }^{3}$ Dr. Renu Bala, \\ ${ }^{4}$ Dr. Vinit Verma, ${ }^{5}$ Dr Krishna P Mazumdar, ${ }^{6}$ Dr. Zile Singh Kundu, \\ ${ }^{7}$ Dr. Kuldeep Singh, \\ ${ }^{I}$ MS Associate Professor, Deptt. Of Orthopaedics, Paraplegia \& Rehabilitation, \\ Pt. BD Sharma PGIMS, Rohtak. \\ ${ }^{2} M S$, Ex-HOD \& Senior Professor, Deptt of Orthopaedics, Paraplegia \& Rehabilitation, \\ Pt BD Sharma PGIMS, Rohtak. \\ ${ }^{3}$ DM, Professor, Department of Anaesthesiology \& Critical Care, Pt BD Sharma PGIMS, Rohtak. \\ ${ }^{4}$ MS, Assistant Professor, Deptt. Of Orthopaedics, Paraplegia \& Rehabilitation, \\ Pt. BD Sharma PGIMS, Rohtak. \\ ${ }^{5}$ MS, Assistant Professor, Deptt. Of Orthopaedics, Paraplegia \& Rehabilitation, \\ Pt. BD Sharma PGIMS, Rohtak. Haryana. \\ ${ }^{6}$ MS, PhD. Senior Professor, Deptt. Of Orthopaedics, Paraplegia \& Rehabilitation, \\ Pt. BD Sharma PGIMS, Rohtak. \\ ${ }^{7}$ Mch, Associate Professor, Burns \& Plastic Surgery, Pt BD Sharma PGIMS, Rohtak
}

\begin{abstract}
:
Introduction: The treatment of severe spinal deformities has always been a difficult task for surgeons. The treatment modalities range from minimal invasive to extensive mobilisation and instrumentation. Halo pelvic traction had proved to be quite effective in correction of these deformities. Hence we intended to study its role in our population with severe spinal deformities.

Materials and Method: The present study involved 25 consenting patient with severe kyphoscoliosis. Preoperative examination and routine investigation were done. Halo-pelvic traction was applied after anterior release. Posterior Fusion was carried out after maximum possible correction achieved. HPT was removed after consolidation of fusion.

Results: The Mean age was 13.88yrs with male:female ratio 1:1. The most common etiologies were congenital or idiopathic. HPT was applied for 22.7weeks. The mean correction of deformity achieved was $38.6^{\circ}$. The complications were primarily minor and temporary. Overall satisfaction rate was good.

Conclusions: The results of our study highlight the importance of HPT as simple and affordable equipment for correction of spinal deformities. The complications, though, do occur, but can be curtailed by careful and proper management.
\end{abstract}

Keywords: spinal deformity, halo-pelvic traction, deformity correction, complications

\section{Introduction}

Spinal deformities are quite common with an incidence of $2.5-25 \%$. The etiology may be congenital defects (segmentation anomalies, hemivertebrae), idiopathic (scoliosis), poliomyelitis, myopathies and post tuberculous collapse of vertebrae. Kyphoscoliosis is a three dimensional deformity comprised mainly of rotation of the vertebrae and deformity in anteroposterior, sagittal and coronal planes. ${ }^{2}$

The management of these deformities varies from non-invasive methods like Risser plaster jacket, Milwaukee brace, Bradford \& Bracket distraction frame to extensive surgical interventions. ${ }^{3}$ The aim of surgery is to halt progress of the deformity, diminish the size of the curve and to restore the trunk balance while improving the patient's quality of life, providing cardiopulmonary stability and avoiding long-term sequelae from restrictive lung disease, painful degeneration and curve decompensation. ${ }^{4-9}$ Anterior spinal surgery \& posterior spinal fusion have long been recognised as the procedure of choice but have not been able to correct all the dimensions of the pathologic process involved in scoliotic spinal deformity. The presence of substantial pulmonary compromise adds to the already formidable surgical procedure. With the degree of the surgical release and segmental instrumentation, the prospective for curve correction is augmented; however, so is the potential for neurologic compromise. ${ }^{8,10-13}$ Throughout the history of development of orthopaedic surgery as a specialty, the understanding and management of spinal deformities has created more than its share of frustration and disappointment. ${ }^{14}$ 
After the advent of Halo traction (halo-femoral, halo-pelvic), better results with fewer complications resulted. ${ }^{15-17}$ In the past, preoperative halo-gravity traction (HGT) was recommended. It was thought to reduce the severity of scoliosis and improve pulmonary function before surgery. ${ }^{18-21}$ Distinct time-dependent mechanical properties of biologic tissues play an important role in viscoelastic behaviour of deformed spines during correction by distraction. Viscoelasticity implies that the behaviour under load is time dependent and that the rate of distraction or the rate of increase in load must be carefully specified during traction procedures used to correct spinal deformities. ${ }^{22}$

The indications of Halo-pelvic traction (HPT) are kyphoscoliosis, double curves, high thoracic curves, curves with high pelvic obliquity. ${ }^{17}$ HPT has the following advantages over other treatment modalities; there is effective, controlled distraction of the spine, during which the patient can be constantly evaluated for any neurological deficit, the patient is mobile, it is the only device that allows a patient with severe restriction of pulmonary function to sit up and even walk soon after surgery without loss of correction, no pressure sore can develop undetected as happens beneath a cast, control of pelvic decompensation of the spine can be eliminated and pelvic tilt or rotation correction, ease of surgery (permits both anterior and posterior approaches in a single procedure). The procedure is not risk free and the myriad of complications have been reported such as pin tract infection, peritoneal penetration by pelvic pins, potential risk of traction to cranial nerves and to the other parts of spine and traction to the cord. ${ }^{23}$ In the light of above findings in the literature, we used this method in our population where no study has been carried out evaluating use of HPT for correction of spinal deformities.

\section{Material \& Methods}

The study was conducted in Department of Orthopaedics, Paraplegia and Rehabilitaion, of our institute. We enrolled 25 patients with severe kyphoscoliosis. The inclusion criteria were; 4-50 yrs age, severe kyphosis, severe rigid scoliosis, scoliosis and kyphoscoliosis (in polimyelitic, neurofibromatosis, paralytic) . Written informed consent from patients or parents (in case of minors) was obtained. All patients were examined thoroughly and neurological status, height of patient and pulmonary function tests were noted. X-ray of spine/deformity [AP \& Lateral view], MRI of the whole spine screening the region involved for status of the cord and clinical photographs (Fig 1a) were obtained. Preoperative chest physiotherapy was taught to the patients.

\section{Procedure:}

In cases of scoliotic deformities, anterior loosening procedure was performed by transthoracic approach. In high spinal deformities it was necessary to mobilize scapula in order to get to underneath for the ribs for the costochondral junctions. The ribs to be removed were marked and cut from the costovertebral and costochondral junction in that order. The segmental vessels were ligated. Disc excision was done through this in the first move by sharp dissection removal of $2 / 3^{\text {rd }}$ of annulus fibrosus followed by removal of nucleus pulposus was done and later the remnants of annulus on the convex side of the curve were removed in the second part, Each intervertebral space cleared was now impacted with gelform and local hemostatics. Bone graft from excised rib was cut to required length and placed in between the vertebral bodies. Intercostal drain was used at closure and at same sitting skull halo was applied in supine position with 4 cranial pins. Two pelvic pins were passed in lateral position to cross the midline and posteriorly exit from the pelvic tubercle. Patients were nursed on split mattresses in post-operative period. The extension bars were fixed after 48 hours of anterior loosening of spine and attachment of pelvic hoop was done and distraction rode were fitted (Stage I). Post-operative period was marked by chest physiotherapy, care of Intercostal drain and patient turning.

Distraction was commenced four days after distraction rods were applied (Fig 1b). Every day each rod was distracted by $1 \mathrm{~mm}$ in four instalments. Patients were screened daily for any complication. Fortnightly radiographs were obtained to monitor curve correction and distraction continued till maximum correction occurs or features of over distraction or any sign of neuropraxia appear before full correction of the deformity.

In the second stage (II), after achieving maximum possible correction, costoplasty \& posterior fusion was done on the patients with HPT in place. Costoplasty was done for cosmetic correction of deformity. It was performed by Leed's method while arthrodesis was performed using Hibb's method. The grafts prepared from the ribs were placed over the denuded bone to achieve fusion. HPT was continued for 16-20 weeks and serial radiographs were taken to monitor fusion. POP Minerva cast was applied after radiological evidence of fusion with the HPT still in place, and the Halopelvic traction unit was removed and neck collar was given for support of head after removal. Finally patients were put on spinal orthosis for maintenance of correction. 

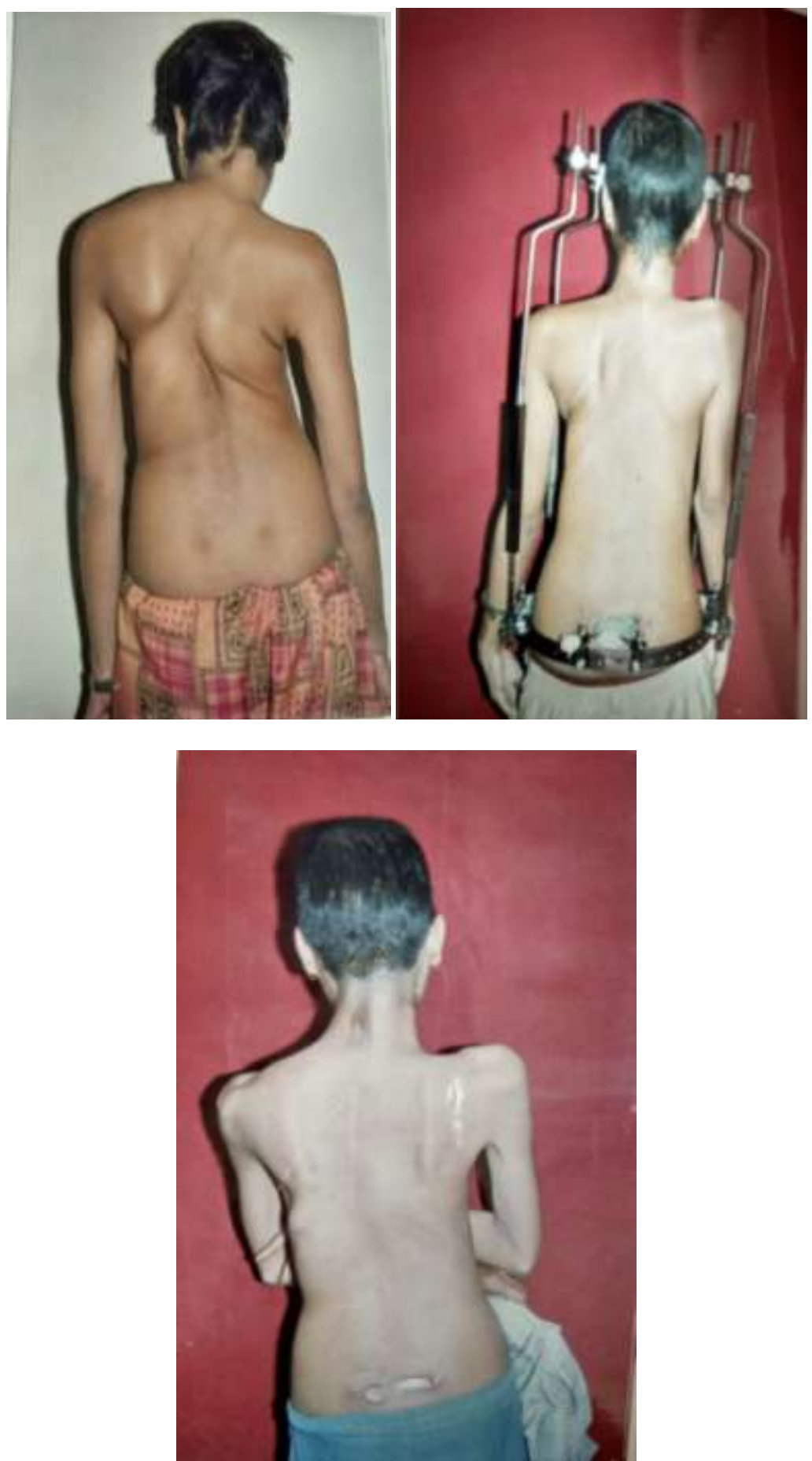

Fig 1 ( a,b and c) Clinical photograph (a) Pre-operative, (b) during halo-pelvic (c) after removal of halo-pelvic final correction

The patients were observed for correction of deformities, increase in height and any complication or untoward event and managed appropriately (Fig 1c).

\section{Observations}

Demographic profile of the patients is shown in table 1. 12/25 had thoracic deformity, 11/25 had thoracolumbar while only $2 / 25$ had cervicothoracic deformity. More than half of the cases had congenital and idiopathic etiology. 17/25 had scoliosis and the remaining 8/25 had kyphosis. There was no side preponderance in scoliotic curves. Most of the patients (92\%) had Scoliosis Research Society type III, IV or V deformity ( Fig 2), i.e. $30^{\circ}$ to $100^{\circ}$. More than $84 \%$ of the patients had the apex vertebra (Cobb's method) in lower thoracic (T6 to T12). The extent of the curve ranged from 4 to 12 vertebrae (Fig 3). Management (table 2) was mostly by 
anterior loosening + HPT + posterior fusion (17/25 cases), in 3/25 only HPT was applied while in 5/25 cases HPT with posterior fusion was done. In $60 \%$ of the patients of scoliosis 3-4 discs were excised to get sufficient anterior loosening to obtain satisfactory correction. The longer the curve, the more the discs excised. On an average of 6-7 vertebrae were fused in $60 \%$ of the patients (Table 3). Costoplasty was done in $3 / 4^{\text {th }}$ of the patients and one-two ribs were excised in most cases. HPT was removed at 14-36 weeks after the end point was reached.

Fig 4 shows the amount of correction achieved following completion of whole procedure. The complications (Table 4) were mostly superficial infection at pelvic pins and temporary traction neuropraxia of cranial nerves which responded well to the treatment. Traction neuropraxia treated with reversal of distraction while pin site infection with the antibiotic and thorough cleaning. About $60 \%$ of the patients as well as parents had good satisfaction with the treatment (table 5).

Table 1 Demographic profile and details of spine deformity

\begin{tabular}{|l|l|l|}
\hline Age (Yrs) & \multicolumn{1}{|c|}{$13.88 \pm 4.06 \quad$ (Mean \pm SD) } & \multicolumn{1}{c|}{$6-22$} \\
\hline Gender (male/female) & $13 / 12$ (number) & $52 \% / 48 \%$ (Percentage) \\
\hline Site of deformity & 2 & $8 \%$ \\
Cervicothoracic & 12 & $48 \%$ \\
Thoracic & 11 & $44 \%$ \\
Thoracolumbar & & \\
\hline Etiology & 13 & $52 \%$ \\
Congenital & 4 & $16 \%$ \\
Idiopathic & 3 & $12 \%$ \\
Tubercular & 4 & $16 \%$ \\
others & & \\
\hline Type of deformity & 8 & $32 \%$ \\
Kyphosis & 17 & $68 \%$ \\
scoliosis & & $52 \%$ \\
\hline Side of curve(scoliosis) & 9 & $48 \%$ \\
Left & 8 & \\
right & & \\
\hline
\end{tabular}

Table 2 Type of surgery performed

\begin{tabular}{|l|l|l|}
\hline Surgery & Number of patients & Percentage \\
\hline Halo-pelvic traction(HPT) & 3 & 12 \\
\hline HPT+posterior fusion & 5 & 20 \\
\hline Anterior loosening+HPT+Posterior fusion & 17 & 68 \\
\hline
\end{tabular}

Table 3 Details of surgery performed

\begin{tabular}{|l|l|l|}
\hline variable & Mean \pm SD & Range \\
\hline Number of ribs excised & $1.88 \pm 0.85$ & $1-4$ \\
\hline Number of discs removed & $4.17 \pm 1.04$ & $3-6$ \\
\hline Number of vertebrae fused & $6.24 \pm 1.04$ & $5-9$ \\
\hline $\begin{array}{l}\text { Duration of immobilization } \\
\text { (in weeks) }\end{array}$ & $22.70 \pm 8.30$ & $14-36$ \\
\hline
\end{tabular}

Table 4 Complications encountered

\begin{tabular}{|l|l|l|}
\hline Related to HPT & 6 & $24 \%$ \\
Infection of pin site & 3 & $12 \%$ \\
Slippage & 2 & $8 \%$ \\
Broken/bending of pin & & \\
\hline Neurological & none & \\
Temporary paresis of spinal cord & 10 & $40 \%$ \\
Neuropraxia of cranial nerves & & \\
& & $12 \%$ \\
\hline General & 3 & $8 \%$ \\
Meralgia paresthetica & 2 & $8 \%$ \\
Superficial infection & 2 & \\
Psychological disturbances &
\end{tabular}

Table 5 Satisfaction level of patients and parents. Data expressed in number and percentage.

\begin{tabular}{|l|l|l|}
\hline Good & 15 & $60 \%$ \\
\hline Fair & 8 & $32 \%$ \\
\hline Poor & 2 & $8 \%$ \\
\hline
\end{tabular}




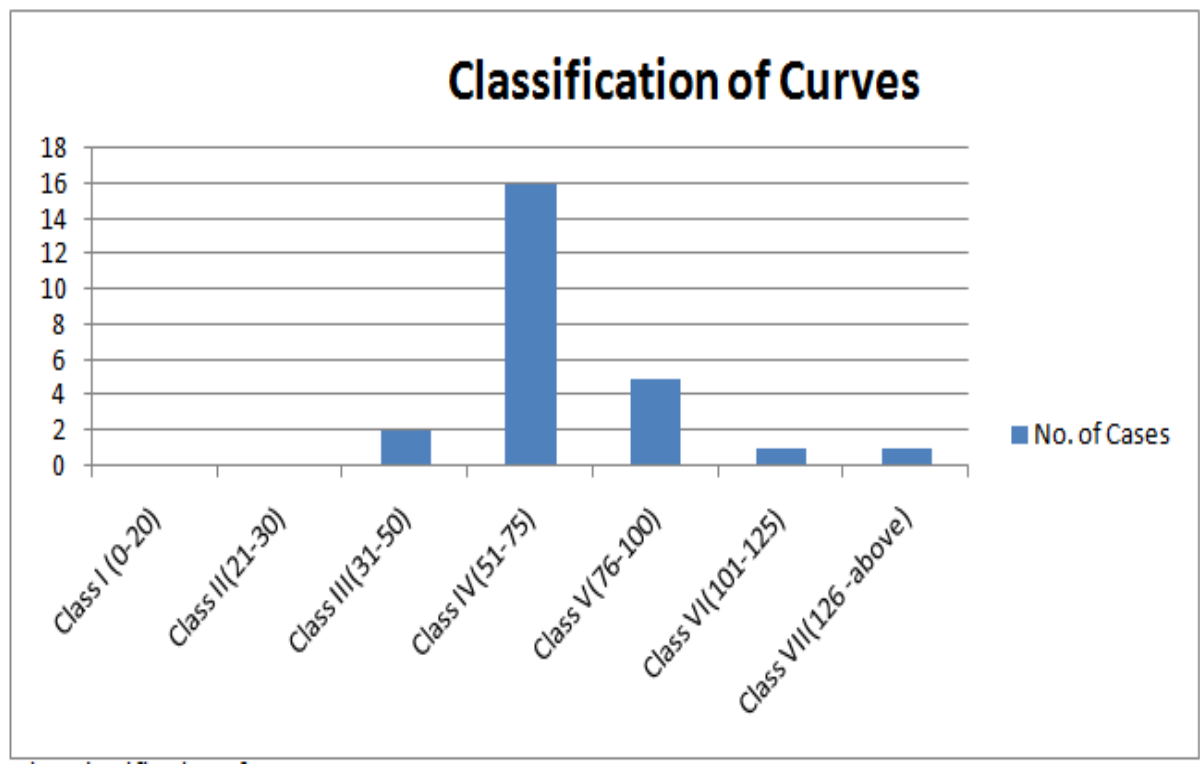

Fig 2 showing classification of curves

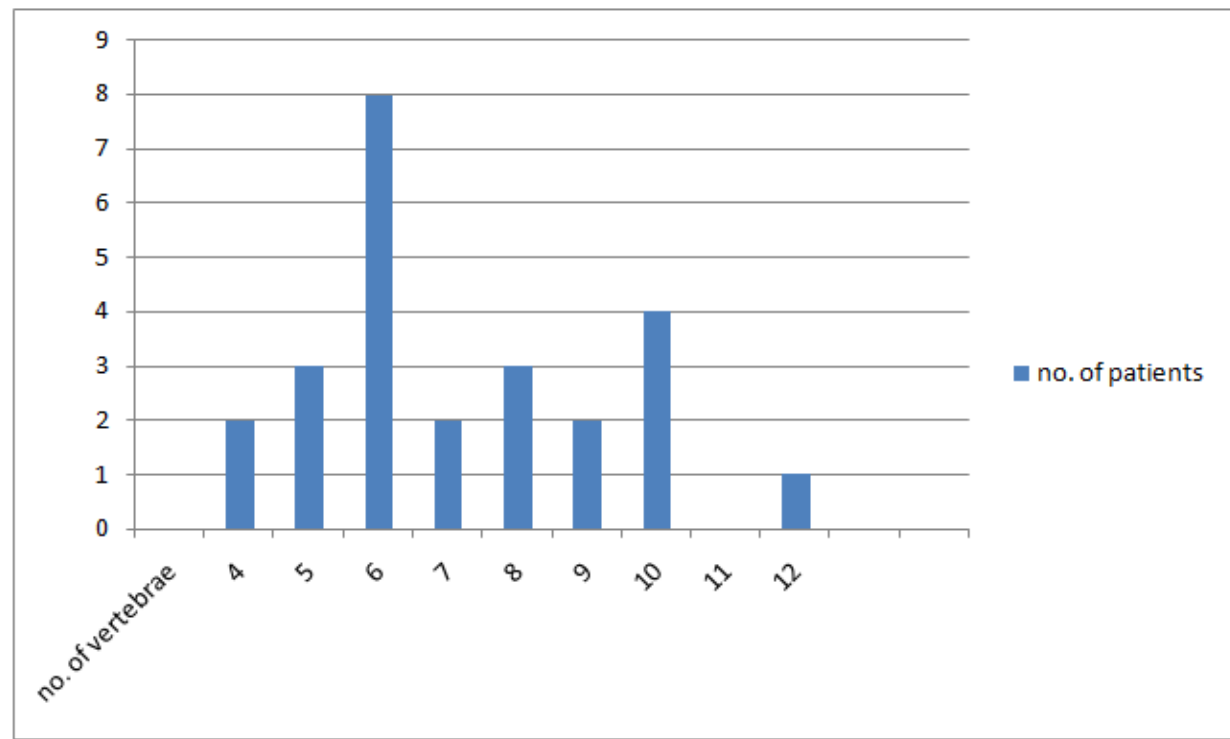

Fig 3 Showing No. of Vertebrae (Extent of curve) involved

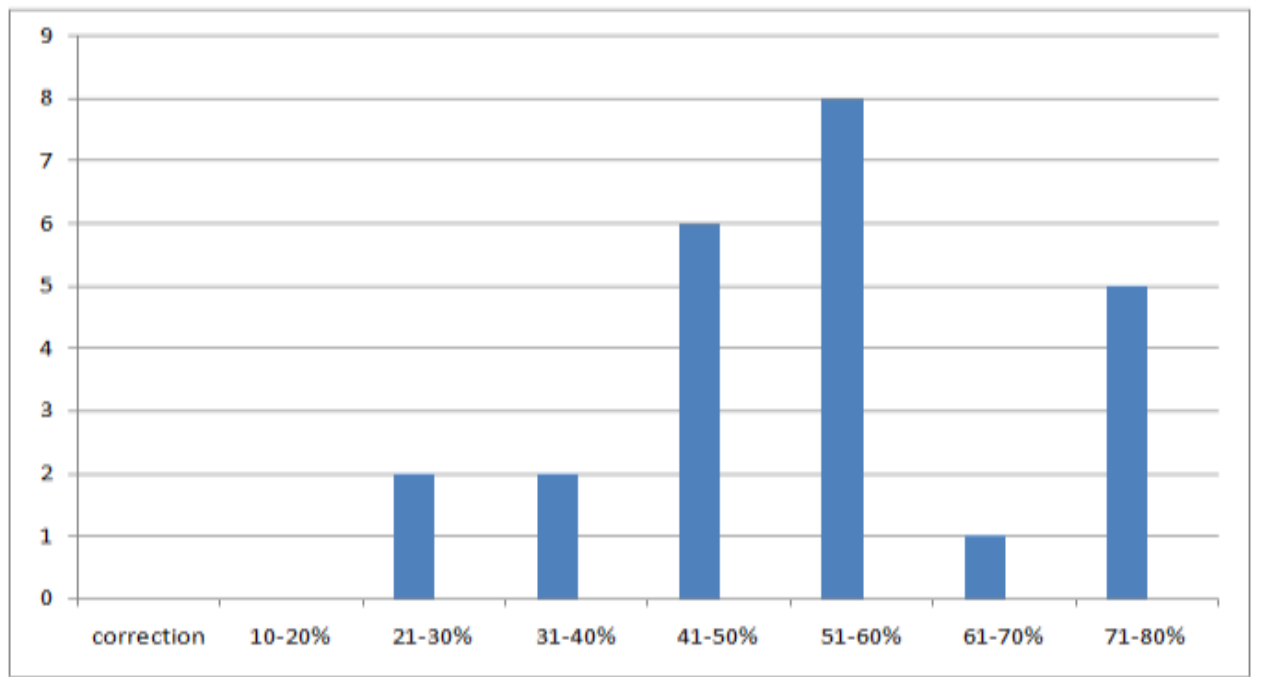

Fig 4 showing percentage of correction achieved 


\section{Discussion}

Orthopaedic surgeons with special interest in spinal problems are always confronted with young patients presented to them with spinal deformities. Various methods have been described for correction these deformities but none is full proof and thus the need for 'Ideal' treatment continues. ${ }^{8}$ Moreover in developing country like india there have been few attempts to study and treat as there are few centers which provide specialized treatment facilities to these patients.

Our study population belongs to young age group (13.8 yrs). In other studies, early age of presentation is reported, but in Indian set up patients presented at later age likely due to lack of health education and facilities of treatment so that deformity becomes severe at the time of presentation. ${ }^{24}$ Male to female ratio was equal. Scoliosis, though, occurs more commonly in females; we had the patients with other deformity too. ${ }^{2,24}$ Females presented earlier than males may be due to early onset of puberty and more concern about cosmosis among females. Most common etiology of spinal deformity is congenital and idiopathic which was observed in our population. ${ }^{1,2}$ In scoliosis thoracic curves are more common and are usually toward right side and at thoracolumbar level more left sided curves were seen. The cobb's angle varied from $50^{\circ}$ to $128^{0}$. In the present study $45^{\circ}$ was taken as the cut off lower limit and the patients above this were taken up for surgical intervention. Patients presenting to us with curve below $45^{\circ}$ were managed conservatively. In our study $8 \%$ of the patients had cobb's angle above $100^{\circ}$. Such patients are at very high risk of neurological injury and cardio-respiratory problems and they can be safely managed with halo-pelvic traction without causing cardio-respiratory and neurological injury to the patient because of the slow distraction applied. ${ }^{\text {ref }}$

Halo-pelvic traction(HPT) was originally devised by Dewald and Ray who termed it 'The University of Illinois Halo Hoop Apparatus'. ${ }^{16}$ Later Morton $\mathrm{J}$ and Mallins used this for correction and maintenance of correction of spinal deformities. ${ }^{25}$ The results of previous studies showed that it was quite effective for correction of deformities. There was controlled distraction of spine, the patient remained mobile and there was minimum discomfort. However this method has its share of complications and pitfalls. In our study majority of the patients underwent both stage I and stage II procedure. We didn't encounter pseudoarthrosis in any of the patient as the apparatus was in place till there was radiolocical evidence of fusion callus. We achieved good correction of the deformity which was $38.6^{0}$. It was slightly more than that by Yau $\operatorname{ACMC}\left(28.3^{0}\right)^{26}$ and $\mathrm{K}$ Otani $\left(23.6^{0}\right)^{27}$. Kalamchi and Ingjald however achieved better correction of deformity in their study. ${ }^{28,29}$

There was around $5.55 \mathrm{~cm}$ increase in sitting height of the patients and the overall improvement in height was $3.91 \mathrm{~cm}$ which corroborates with studies in the literature ${ }^{30,31}$ This may be because of both correction of deformity as well as growth of unfused part of spine in halo pelvic traction during period of immobilization.

Halo pelvic traction is a very demanding regimen in correction of deformities and complications were encountered though there were no serious complications. The instrument related problems were slipping of pins, infection at the site of pelvic pins. To prevent these complications cranial pins need to be regularly tightened with torque limiting screw driver and daily bath as well as regular and meticulous cleansing of the pins with spirit and tincture iodine should be done. Among neurological complications most common were temporary traction neuropraxia of cranial nerves most common being abducent nerve. The measures like adequate treatment of intraspinal soft tissue and bony pathology, adequate pre-tractional anterior loosening of spine and shortening of column, slow and gradual distraction immediate reserval of the traction forces if any sign appears should be adopted in order to prevent them.

Every curve and deformity has its own personality and consistently attempting only one line of procedure on each and every case would be unjustified. Each Case should be studied individually and type of management be decided as per risk and reward policy. Halo-pelvic traction has been criticized for its complications but it is a simple and effective tool for correction of spinal deformities in our country where infrastructure for advanced spine surgery are very few and in conditions where instrumentation of spine cannot be carried out because severe osteoporosis as well as other technical difficulties. Appropriate measures should be taken to keep the risk / complications at an absolute minimum and the reward from correction can be most gratifying to both patient and surgeon.

\section{References}

[1]. Carter OD, Haynes SG: Prevalence rates for scoliosis in U S adults: Results from first National Health and Nutrition Examination Survey. Int J Epidemiol 1987; 16:537-44.

[2]. Christopher RG, Joshua DA, Patrick TO and Thomas CS. Adult spine deformity. Curr Rev Musculoskelet Med. 2011 Dec; 4(4): 159-167.

[3]. Hibbs R, Risser J, Ferguson A. Scoliosis treated by the fusion operation an end-result study of three hundred and sixty cases. J Bone Joint Surg. 1931 Jan;13(1):91-104.

[4]. Zhang JG, Wang W, Qiu GX, Wang YP, WengXS, Xu HG. The role of preoperative pulmonary function tests in the surgical treatment of scoliosis. Spine. 2005 Jan 15;30(2):218-21.

[5]. Weinstein SL. Natural history. Spine. 1999 Dec 15;24(24):2592-600.

[6]. Pehrsson K, Danielsson A, Nachemson A. Pulmonary function in adolescent idiopathic scoliosis: a 25 year follow up after surgery or start of brace treatment. Thorax. 2001 May;56(5):388-93. 
[7]. Vitale MG, Matsumoto H, Bye MR, Gomez JA, Booker WA, Hyman JE, et al. A retrospective cohort study of pulmonary function, radiographic measures, and quality of life in children with congenital scoliosis: an evaluation of patient outcomes after early spinal fusion. Spine. 2008 May 15;33(11):1242-9.

[8]. Rizzi PE, Winter RB, Lonstein JE, Denis F, PerraJH. Adult spinal deformity and respiratory failure. Surgical results in 35 patients. Spine. 1997 Nov 1;22(21):2517-2530; discussion 2531.

[9]. Jackson RP, Simmons EH, Stripinis D. Coronal and sagittal plane spinal deformities correlating with back pain and pulmonary function in adult idiopathic scoliosis. Spine. $1989 \mathrm{Dec} ; 14(12): 1391-7$.

[10]. Hodgson AR, Stock FE. Anterior spinal fusion a preliminary communication on the radical treatment of Pott's disease and Pott's paraplegia. Br J Surg. 1956 Nov; 44 (185):266-75.

[11]. BuchowskiJM, Skaggs DL, Sponseller PD. Temporary internal distraction as an aid to correction of severe scoliosis.Surgical technique. J Bone Joint Surg Am. 2007 Sep;89 Suppl 2 Pt.2:297-309.

[12]. Suk S-I, Kim J-H, Kim W-J, Lee S-M, Chung E-R, Nah K-H. Posterior vertebral column resection for severe spinal deformities. Spine. 2002 Nov 1;27(21):2374-82.

[13]. Di Silvestre M, Bakaloudis G, Lolli F, Vommaro F, Martikos K, Parisini P. Posterior fusion only for thoracic adolescent idiopathic scoliosis of more than 80 degrees: pedicle screws versus hybrid instrumentation. Eur Spine J Off PublEur Spine SocEur Spinal Deform SocEur Sect Cerv Spine Res Soc. 2008 Oct;17(10):1336-49.

[14]. Moe JH. Complications of scoliosis treatment. Clin Orthop. 1967 Aug; 53:21-30.

[15]. Perry J, Nickel VL. Total cervicalspine fusion for neck paralysis. J Bone Joint Surg Am. 1959 Jan;41-A(1):37-60.

[16]. Dewald RL, Ray RD. Skeletal traction for the treatment of severe scoliosis. The University of Illinois halo-hoop apparatus. J Bone Joint Surg Am. 1970 Mar; 52(2):233-8.

[17]. O'Brien JP, Yau AC, Smith TK, Hodgson AR. Halo pelvic traction. A preliminary report on a method of external skeletal fixation for correcting deformities and maintaining fixation of the spine. J Bone Joint Surg Br. 1971 May;53(2):217-29.

[18]. Rinella A, Lenke L, Whitaker C, Kim Y, Park S, Peelle M, et al. Perioperative halo-gravity traction in the treatment of severe scoliosis and kyphosis. Spine. 2005 Feb 15;30(4):475-82.

[19]. Sponseller PD, Takenaga RK, Newton P, Boachie O, Flynn J, Letko L, et al. The use of traction in the treatment of severe spinal deformity.Spine. 2008 Oct 1;33(21):2305-9.

[20]. Letts RM, Palakar G, Bobecko WP. Preoperative skeletal traction in scoliosis. J Bone Joint Surg Am. 1975 Jul;57(5):616-9.

[21]. Winter RB, Lonstein JE. The Moe Maximal Correction Test to determine true curve flexibility: a historical note with current application. Spine. 2010 Aug 15;35(18):1733-5.

[22]. Clark J, Louis C, Yau A. Viscoelastic behaviour of deformed spines under correction with halo-pelvic disctraction. Clin Orthop. 1975;(110):90-111.

[23]. Ransford AO, Manning CWSF. Complications of halo pelvic distraction for scoliosis. J Bone Joint Surg. 1975; 57 B (2). 332 336.

[24]. Rogala EG, Drummond DS, Gurr J. Scoliosis: incidence and natural history. JBone Joint Surg 1978; 60A $173-6$.

[25]. Morton J, Malins P. The correction of spinal deformities by halo-pelvic traction. Physiotherapy. 1971 Dec;57(12):576-81.

[26]. Yau ACMC, Hso LCS,O'Brain JP, Hodgson AR. Tubercular kyphosis - correction with spinal osteotomy, Halo -pelvic distraction and posterior fusion. J Bone Joint Surg1974; 56A (7): 1419-1434.

[27]. Otani K,Satomi K, FuzimuraY, Manzoku S, Shibashaki K. Spinal osteotomy to correct kyphosis in spinal tuberculosis.International Orthop1979; 3: 229-235.

[28]. Kalamchi A, Yau ACMC, O’Brian JP, Hodgson AR. Halo pelvic distraction apparatus - AN analysis of 150 consecutive patients, J Bone Joint Surg 1976; 58 A (8): 1119-24.

[29]. Bjerkreim I, Magnaes B, Semb G. Surgical treatment of severe angular kyphosis. Acta Orthop Scand 1982; 53: $913-917$.

[30]. Nordwall A. Studies in Idiopathic scoliosis. Acta Orthop Scand 1973;Suppl. 150: 70-163.

[31]. Archer IA, Dickson RA. Stature and Idiopathic Scoliosis. J Bone Joint Surg 1985; 67B: 185-88. 